\title{
As mulheres na agricultura familiar de Mirassol D'Oeste/MT: reflexões sobre a produção e políticas
}

\begin{abstract}
Objetivou-se investigar a atuação das mulheres na agricultura familiar de Mirassol D'Oeste/MT, a partir do estudo de caso da Associação de Hortifrutigranjeiros. O delineamento da pesquisa é qualitativo. Foi realizado a pesquisa bibliográfica, análise de documentos de órgãos oficiais, coleta de dados através de formulários composto por perguntas abertas e fechadas, a utilização de máquina fotográfica para o registro dos lugares visitados. Para obtenção de informações sobre o número de mulheres na Associação foram realizadas visitas à Secretaria municipal de Agricultura, cujo cadastro estava desatualizado. A pesquisa foi realizada com as mulheres na Associação por meio de entrevista semiestruturada, com auxílio de formulário. Os dados foram tabulados e gerados as frequências absoluta e relativa. Verificou-se que a burocracia das políticas públicas e a incipiência da assistência técnica agrícola dificultam o acesso as políticas específicas, como o Programa Nacional da Agricultura Familiar-Mulher. Além disso, às agricultoras da Associação de Hortifrutigranjeiros almejam a organização documental para que possam coletivamente, propor projetos que contemplem as necessidades do grupo e, consequentemente, oferecer melhores produtos para comercialização na feira municipal. Concluiu-se que por meio da produção oriunda da agricultura familiar as mulheres da Associação de Hortifrutigranjeiros contribuem na renda familiar, contudo necessitam melhorar a organização da associação para acessarem as políticas públicas.
\end{abstract}

Palavras-chave: Agricultura Familiar; Gênero; Políticas Públicas.

\section{The role of women in family farming in Mirassol D'Oeste - Mato Grosso state: reflexions about the production and policies}

\begin{abstract}
The objective of this study was to investigate the role of women in the family farming of municipality Mirassol D'Oeste / Mato Grosso State, based on the case study from the Association of Fruit and Vegetable Farmers. The research design is qualitative. It was carried out the bibliographic research, analysis of documents of official organs, data collection through forms composed of open and closed questions, the use of a camera to record the places visited.To obtain information on the number of women in the Association, visits were made to the Municipal Department of Agriculture, whose register was outdated. The research was carried out with women from the Association using a semi-structured interview, aided with a form. Data were tabulated and the absolute and relative frequencies generated. It was verified that the bureaucracy of public policies and the incipience of agricultural technical assistance make it difficult to access specific policies such as the National Family Farming Program for Women. In addition, the feminine members of the Association of Fruit and Vegetable Farmers aim at a documentary organization so that they can collectively propose projects that meet the needs of the group and, consequently, offer better products for commercialization at the municipal fair. It was concluded that through the production from family farming, women from the Association of Fruit and Vegetable Farmers contribute to family income, but they need to improve the organization of the Association to access public policies.
\end{abstract}

Keywords: Family Agriculture; Genus; Public Policies.

Topic: Química Agrícola e Ambiental

Reviewed anonymously in the process of blind peer.

Hellen Simone Tortorelli

Universidade Federal de Mato Grosso, Brasil

http://lattes.cnpq.br/9878130708643851

hellentortorelli@gmail.com

Sandra Mara Alves da Silva Neves

Universidade Federal de Mato Grosso, Brasil

http://lattes.cnpq.br/6430066425008976

ssneves@unemat.br

Ronaldo José Neves

Universidade Federal de Mato Grosso, Brasil

http://lattes.cnpq.br/5794831112557727

hellentortorelli@gmail.com
Received: 19/04/2016

Approved: 21/05/2016

Raimundo Nonato Cunha de França

Universidade Federal de Mato Grosso, Brasil

http://lattes.cnpq.br/1084147613800807

raimundofranca@unemat.br

Edinéia Aparecida dos Santos Galvanin

Universidade Federal de Mato Grosso, Brasil

http://lattes.cnpq.br/5041881204275768

galvanin@gmail.com

Referencing this:

TORTORELLI, H. S.; NEVES, S. M. A. S.; NEVES, R. J.; FRANÇA, R. N. C.; GALVANIN, E. A. S.. As mulheres na agricultura familiar de Mirassol D'Oeste/MT: reflexões sobre a produção e políticas. Revista IberoAmericana de Ciências Ambientais, v.8, n.1, p.140-151, 2017. DOI: http://doi.org/10.6008/SPC2179-6858.2017.001.0012 


\section{INTRODUÇÃO}

A agricultura familiar é denominada como importante fonte de renda para o autoconsumo daqueles que sobrevivem em pequenos espaços produtivos, principalmente para os agricultores familiares no interior do País. No contexto apresentado como análise, o estudo de caso das agricultoras familiares da Associação de Hortifrutigranjeiros no município mato-grossense de Mirassol D’ Oeste, com enfoque na atuação das mulheres.

Nesse sentido, a agricultura familiar como importante forma de autoconsumo daquelas pessoas que trabalham em pequenos espaços produtivo sendo este, considerado como uma das principais atividades econômicas no município de Mirassol D’Oeste/MT, sob esse viés vale destacar a importante política pública, o Programa Nacional da Agricultura Familiar (PRONAF).

Dentro da abordagem da agricultura familiar Schneider (2003, p.100) expôs que:

De outro lado, a afirmação da agricultura familiar no cenário social e político brasileiro estão relacionados à legitimação que o Estado Ihe emprestou ao criar, em 1996, o Pronaf (Programa Nacional de Fortalecimento da Agricultura Familiar). Esse programa, formulado como resposta às pressões do movimento sindical rural desde o início dos anos de 1990, nasceu com a finalidade de prover crédito agrícola e apoio institucional às categorias de pequenos produtores rurais que vinham sendo alijados das políticas públicas ao longo da década de 1980 e encontravam sérias dificuldades de se manter na atividade.

Buainain et al. (2003), discorreram que a agricultura familiar é significativa para o desenvolvimento do País, pois contribui na manutenção de recursos naturais, produção de alimentos, com destaque para a atuação das mulheres, entre outros fatores relevantes. Teixeira (2002) acrescentou que as estratégias de desenvolvimento para os agricultores familiares se definem a partir das políticas públicas. Sousa (2011) apontou que as políticas públicas definem grupos de uma determinada região e que, a ausência, destas políticas gera dificuldades para que as pessoas fixarem no lugar, o que resulta na saída destas pessoas do campo para a cidade gerando um desequilíbrio social urbano - êxodo rural.

No tocante a discussão de gênero na agricultura familiar vale mencionar que além das atividades domésticas, as mulheres realizam outros trabalhos, que não têm o merecido reconhecimento diante os desafios existentes ao que emerge o trabalho no campo e direitos das mulheres rurais.

Corroborando com exposto Choinnaski (1998, p. 226) discorreu que:

A realidade no campo, no início dos anos 80 , era a seguinte: nós, camponesas, não tínhamos nenhuma participação, nem no sindicato, nem na cooperativa ou na política. Não éramos reconhecidas como trabalhadoras e cidadãs. Principalmente por meio da Igreja, começaram a discussão e a articulação de oposições aos sindicatos pelegos. Nesse mesmo período, também houve a necessidade de se fazer a sindicalização das mulheres. Porém, as mulheres ajudavam a ganhar os sindicatos e não tinham participação como associadas, e muito menos nas direções. Começou se a discutir, então, a organização das mulheres, o Movimento de Mulheres Agricultoras.

Desse modo, outra iniciativa importante, foi à criação em 2001 do "Programa de Ações afirmativas para Promoção de Igualdade e Oportunidade de Tratamento entre Homens e Mulheres", vinculado ao MDA - Ministério do Desenvolvimento Agrário que visou responder diretamente as demandas dos movimentos de mulheres trabalhadoras rurais.

Mendes (2014) afirmou que as mulheres são responsáveis por cerca de $45 \%$ da produção de 
alimentos na América Latina. Cerca de 15 milhões de trabalhadoras do campo não tem acesso a política pública destinada especificamente a agricultura familiar e reforma agrária, nesse viés vale destacar que, estas mulheres rurais não têm acesso a outras políticas públicas, ou vivem na linha de pobreza por não acessarem os programas sociais em esfera municipal, estadual e federal, outro índice expressivo da população do campo, é que as mulheres equivalente a $45 \%$ da população rural, e uma parcela significativa não possuem documentos essenciais, tais como: cadastro de pessoa física, o registro de identificação geral e carteira de trabalho.

As agricultoras da Associação de Hortifrutigranjeiros do município de Mirassol D’ Oeste afirmam que não conhecem as políticas públicas específicas para mulher do campo e, ainda assim, enfatizam a importância de se organizarem para atuem junto à Associação.

Do Carmo (2001) expôs sobre a importância dos espaços rurais, pois a característica da agricultura familiar apresenta fatores sociais e políticas públicas possam se aliar para o bem comum de todos, norteando à sustentabilidade, a solidariedade, a inclusão social e principalmente ao que realce as mudanças necessárias nas relações de gênero.

Vale ainda destacar que, as políticas públicas surgem como uma análise de uma determinada realidade em diversos contextos socioculturais, onde grupos com interesses comuns vão direcionar a política no contexto da sua necessidade de modo que, possam garantir possíveis soluções que atendam os desafios do coletivo.

Apesar de optar por abordagens diferentes, as definições de políticas públicas assumem, em geral, uma visão holística do tema, uma perspectiva de que o todo é mais importante do que a soma das partes e que indivíduos, instituições, interações, ideologia e interesses contam, mesmo que existam diferenças sobre a importância relativa destes fatores. (SOUZA, 2006, p. 25)

As agricultoras mencionadas neste trabalho produzem os alimentos (legumes, hortaliças e massas) em seus espaços produtivos, visando contribuir na ampliação da renda familiar. $\mathrm{O}$ apoio que recebem da Prefeitura Municipal, por meio da Secretaria de Agricultura, ocorre através do Encontro Mulher Rural que acontece em parceria com outras associações e órgãos públicos, com intuito de divulgar ações de agricultoras de Mirassol D'Oeste/MT.

Como exemplo, vários grupos de mulheres sejam estas rurais ou urbanas lutam através de movimentos sociais, por reivindicações e direitos apontando no contexto o direito trabalhista através da previdência social que, necessitam serem reformulados conforme as particularidades de cada grupo, melhorias estas que visam igualar aos direitos do homem. As mulheres, nas últimas décadas do século $\mathrm{XX}$, emergem em diferentes cenários como sujeitos sociais, históricos e econômicos e vão se constituindo em metade da força de trabalho mundial. Isso tudo provoca uma reviravolta na condição da mulher tanto no que se refere a avanços quanto em impactos sobre suas vidas, pois elas constroem lutas e resistem à opressão, enfrentando os mais diversos mecanismos de discriminação. (MENDES et al., 2014, p.75)

Nesse sentido, as agricultoras da Associação de Hortifrutigranjeiros acreditam ser necessário o fortalecimento das mulheres do campo por meio de Políticas Públicas em âmbito regional e como agenda permanente de governo, seja nas esferas municipal, estadual ou federal. Face ao exposto, objetivou-se 
investigar a atuação das mulheres na agricultura familiar de Mirassol D'Oeste/MT, a partir de um estudo de caso da Associação de Hortifrutigranjeiros.

\section{METODOLOGIA}

O município de Mirassol D'Oeste integra a região Sudoeste de planejamento do estado de Mato Grosso (MATO GROSSO, 2012), com área geográfica de 1.072,54 km², distando 329 km da capital, Cuiabá (Figura 1). Com população de 25.299 habitantes, sendo que 21.470 residem na área urbana e os demais no distrito de Sonho Azul e nas propriedades rurais (IBGE, 2016).

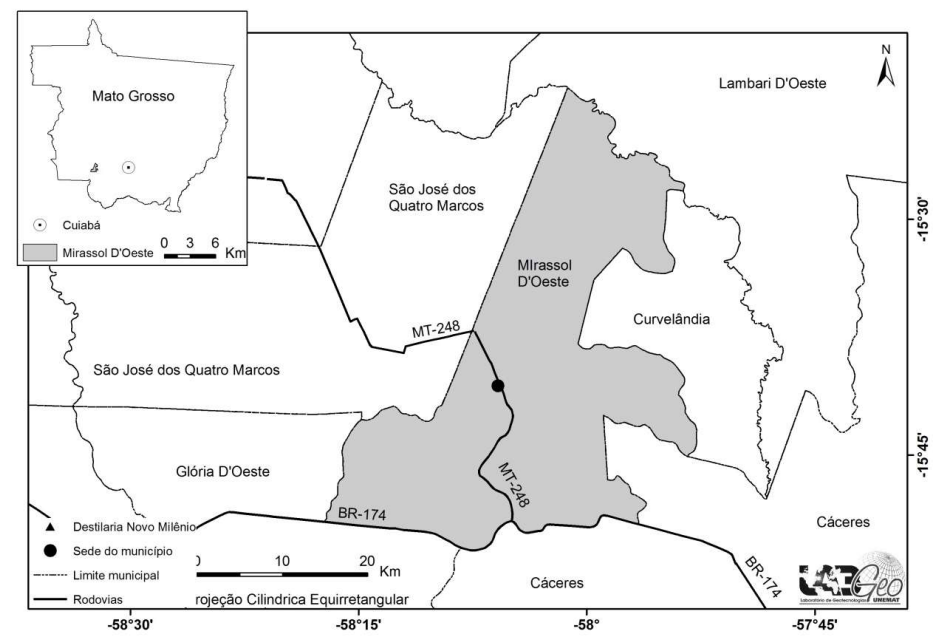

Figura 1: Município de Mirassol D’ Oeste nos contextos estadual e municipal. Fonte: KREITLOW (2015).

O presente estudo, cujo foco das discussões pauta-se na questão de gênero, agricultura familiar e políticas públicas, utiliza como estudo de caso as agriculturas vinculadas à Associação de Hortifrutigranjeiros do município de Mirassol D’Oeste - MT para realização de análises derivadas da compreensão das referências consultadas.

Para execução deste trabalho foram adotados os procedimentos metodológicos das pesquisas bibliográfica, documental e de campo (MARCONI e LAKATOS, 2007), efetuando-se a revisão em textos científicos, consulta a documentos oficiais e obtenção de informações junto as atoras sociais em seus locais de trabalho, respectivamente.

Yin (2010) define o estudo de caso como uma importante estratégia metodológica para a pesquisa em ciências humanas, o que permite que o investigador aprofunde no fenômeno estudado, favorecendo uma visão holística sobre os acontecimentos da vida real, destacando - se seu caráter de investigação empírica de fenômenos contemporâneos.

O Sistema de Posicionamento Global (GPS) foi utilizado para georreferenciamento da Associação de Hortifrutigranjeiros e a câmera digital para os registros fotográficos dos locais visitados. Os dados foram inseridos no Banco de Dados Geográfico (BDG) no software ArcGis, versão 10.4 (ESRI, 2016).

A identificação das agricultoras para a entrevista foi realizada por meio do método "Snowball Sampling" (COLEMAN, 1958; GOODMAN, 1961; SPREEN, 1992), que é uma técnica de amostragem não probabilística, normalmente utilizada quando as populações são desconhecidas ou raras. 
Por meio de trabalho de campo na feira livre municipal de Mirassol D’Oeste/MT, foram entrevistadas vinte agricultoras associadas. No início da entrevista foi apresentada a proposta da pesquisa as agricultoras e foi-Ihes solicitada à adesão ao termo de consentimento livre e esclarecido (TCLE). Esta pesquisa foi submetida ao Comitê de Ética da Universidade do Estado de Mato Grosso, a qual foi deferida pelo Parecer CEP UNEMAT $n$ ㅇ 1.449.552/2016.

A Associação de Hortifrutigranjeiros encontra-se com cadastro dos associados desatualizado. 0 contato com as agricultoras na Associação foi essencial para que fosse estabelecido posteriormente, o diálogo com estas nos espaços produtivos onde se originam a produção alimentícia com base familiar, que abastece a feira livre municipal. Foi utilizado formulário semiestruturado, cujo pré-teste foi realizado junto as agriculturas da Associação de Hortifrutigranjeiros.

Os dados obtidos foram tabulados na planilha Excel, cujas respostas foram decompostas em campos e agrupadas por Frequência Absoluta para a análise, interpretação e compreensão em termos percentuais (Frequência Relativa) (OLIVEIRA et al., 2014). Posteriormente, foram geradas tabelas e figuras que auxiliaram no estabelecimento das análises e discussão.

\section{RESULTADOS E DISCUSSÃO}

Na questão de gênero percebe-se que as mulheres obtiveram avanços referentes aos direitos de igualdade social frente ao patriarcalismo histórico no País. Corroborando com o exposto, Mendes et al. (2014, p. 75) expuseram que

As mulheres, nas últimas décadas do século $\mathrm{XX}$, emergem em diferentes cenários como sujeitos sociais, históricos e econômicos e vão se constituindo em metade da força de trabalho mundial. Isso tudo provoca uma reviravolta na condição da mulher tanto no que se refere a avanços quanto a impactos sobre suas vidas, pois elas constroem lutas e resistem à opressão, enfrentando os mais diversos mecanismos de discriminação.

Tavares (2011) enfatizou que o estado brasileiro não conseguiu cumprir o exercício de cidadania com a maioria de suas mulheres (rurais, indígenas, negras, pobres) e que atualmente vivenciam a exclusão social. Além disso, há o baixo percentual nos índices de estatísticas governamentais, ao que tange a violência doméstica feminina. As mulheres têm sido de fundamental importância para o desenvolvimento da agricultura. Diante o exposto, Cintrão e Siliprandi (2011, p.188) expuseram que

em 2003, no início do governo Lula, foi criada a Secretaria Especial de Políticas para as Mulheres, com status de Ministério, responsável pela realização de duas Conferências Nacionais de Políticas para as Mulheres (em 2004 e 2007). Destas conferências resultaram os Planos Nacionais de Políticas para as Mulheres I e II. Em ambos os eventos houve significativa participação das mulheres rurais, que exigiram políticas que as beneficiassem como trabalhadoras e como moradoras do meio rural, enfocando problemas tais como o acesso à documentação civil, a terra, ao crédito, a assistência técnica e a organização produtiva. As mulheres trouxeram ainda para as conferências suas preocupações com relação ás questões ambientais, com a falta de infraestrutura no meio rural e com o enfrentamento da violência contra a mulher. Seu aparecimento público nesses eventos se deu na forma de múltiplas identidades e organizações. Sindicatos, federações, associações, cooperativas, e diferentes grupos de base e movimentos sociais trouxeram as reivindicações de acampadas, assentadas da reforma agrária, agricultoras familiares, quilombolas, pescadoras artesanais, extrativistas, indígenas, ribeirinhas, quebradeiras de coco babaçu, ou simplesmente "mulheres do campo e da floresta". 
As mulheres da Associação de Hortifrutigranjeiros no município de Mirassol D’ Oeste/MT consideram que a participação feminina na comercialização aumentou no decorrer dos anos, mas ressalvaram a baixa participação e desinteresse das jovens em dar continuidade ao trabalho na agricultura familiar. $\mathrm{O}$ sonho das jovens filhas das associadas é prosseguir com os estudos após a conclusão do Ensino Médio, que geralmente cursam na cidade. Utopia esta possível de concretização, pois há disponibilidade de cursos de graduação nos municípios de Cáceres, São José dos Quatro Marcos e Araputanga, que estão situados próximos a Mirassol D' Oeste.

Desse modo, ao apresentar as características das agricultoras familiares da Associação de Hortifrutigranjeiros, constatou-se que a faixa etária compreende de 26 anos a 56 anos (Tabela 1). Em relação à força produtiva de trabalho ao que tange a comercialização de produtos na feira livre municipal de Mirassol D'Oeste/MT, apenas $8,69 \%$ representam as agricultoras na faixa etária de 30 anos.

Entretanto, as mulheres idosas da Associação de Hortifrutigranjeiros afirmam que aprenderam ainda jovens, a arte de preparar a terra, plantar, colher e comercializar os alimentos para garantir auxílio na renda familiar. O que corrobora com o exposto por Brumer (2004, p. 211): "Nessa esfera, as mulheres têm autonomia e poder, tomando decisões relativas ao preparo dos alimentos, cuidado da casa e da roupa, orientação e dos filhos, assim como ao uso de recursos destinados ao consumo doméstico".

Nesse sentido, a Organização das Nações Unidas - ONU (1995) apontou em relatórios que as mulheres de todas as regiões do mundo são responsáveis por $53 \%$ do trabalho total, incluindo o trabalho não remunerado nos países em desenvolvimento e 51\% nos países industrializados.

Tabela 1: Idade das agricultoras da Associação de Hortifrutigranjeiros no município de Mirassol D’Oeste, MT.

\begin{tabular}{ccr}
\hline Idade (anos) & FA & FR (\%) \\
\hline 45 & 1 & 4,34 \\
46 & 1 & 4,34 \\
43 & 1 & 4,34 \\
42 & 1,34 \\
28 & 1 & 4,34 \\
36 & 1 & 4,34 \\
47 & 1 & 4,34 \\
40 & 1 & 4,34 \\
30 & 1 & 8,69 \\
38 & 2 & 4,34 \\
56 & 1 & 4,34 \\
53 & 1 & 4,34 \\
44 & 1 & 4,34 \\
42 & 1 & 4,34 \\
48 & 1 & 4,34 \\
31 & 1 & 4,34 \\
26 & 1 & 4,34 \\
43 & 1 & 4,34 \\
52 & 1 & 4,34 \\
Recusaram & 1 & 13,04 \\
\hline TOTAL & 3 & 100 \\
\hline
\end{tabular}

As mulheres da Associação de Hortifrutigranjeiros consideram seu trabalho como importante, pois é o lugar onde sentem autonomia além do "cuidar de casa". Elas afirmaram que, sentem amor pelo que fazem há anos nessa entidade, desde a "antiga feira" que era localizada na praça próxima a rodoviária municipal de 
Mirassol D’ Oeste. E acrescentaram que há necessidade de mudanças para que a Associação se consolide conforme consta nos objetivos de seu Estatuto.

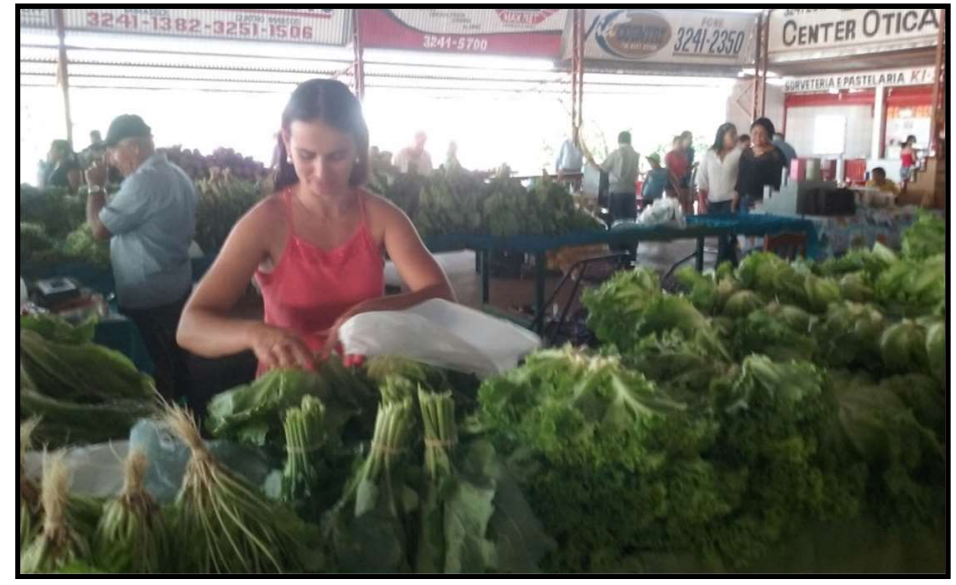

Figura 2: Jovem contribuindo no trabalho de comercialização de verduras, cuja mãe é membro da Associação de hortifrutigranjeiros no município de Mirassol D’Oeste/MT. Fonte: a autora (2016).

As agricultoras cuja maioria é casada (Tabela 2) afirmaram que os maridos ajudam na produção dos alimentos através do plantio e organização do espaço rural, cabendo a elas principalmente a função de comercialização. Uma das entrevistadas relatou gostar do trabalho de vender e que as mulheres são mais simpáticas na hora de conquistar os clientes na feira, pois uma vez conquistado o cliente que vai "fazer feira" esta cria o vínculo, comprando anos e anos na mesma banca.

Tabela 2: Estado civil das agricultoras da Associação de hortifrutigranjeiros no município de Mirassol D’Oeste, MT.

\begin{tabular}{lcrr}
\hline & Estado civil & FA & FR (\%) \\
\hline Casadas & & 13 & 56,52 \\
Solteiras & & 3 & 13,04 \\
Viúvas & & 1 & 4,34 \\
União estável & & 3 & 13,04 \\
Recusas & & 3 & 13,04 \\
\hline & Total & 23 & 100 \\
\hline
\end{tabular}

As agricultoras mirassolenses da Associação consideram que o trabalho da mulher no campo é decisivo para a garantia da segurança alimentar e, em muitos casos, para a manutenção da unidade produtiva (Figura 3). De acordo com a importância do papel desempenhado pelas mulheres, Scott et al. (2010, p. 590) corroboram ao expor que elas são:

Responsáveis pela alimentação familiar, plantam, cuidam das crianças, participam da colheita, preparam as refeições, arrumam e limpam a casa, lavam roupas e louças, cuidam do quintal e dos animais de pequeno porte, carregam ferramentas, limpam os roçados, participam de mutirões, e ainda assim seu trabalho não é visualizado, são vistas como estando apenas "ajudando" seus maridos ou seus pais.

Nesse sentido, Brito (2000) mencionou que as mulheres realizam expressiva carga de trabalho não pago, além do cuidar da família e do trabalho doméstico, estes tomam boa parte do tempo da mulher, considerando que estes fatores devem receber atenção exclusiva, pois, reproduzem consideravelmente a desigualdade social.

Silva (2014) versa que, na região sudoeste da grande Cáceres-MT o que gera consideravelmente excedente para a comercialização é a agricultura familiar, mas os produtos não são competitivos em virtude 
do transporte, que gera um custo considerado alto para os agricultores, e que consequentemente, eleva os valores do produto final, tornando-os "caros" para a comercialização.
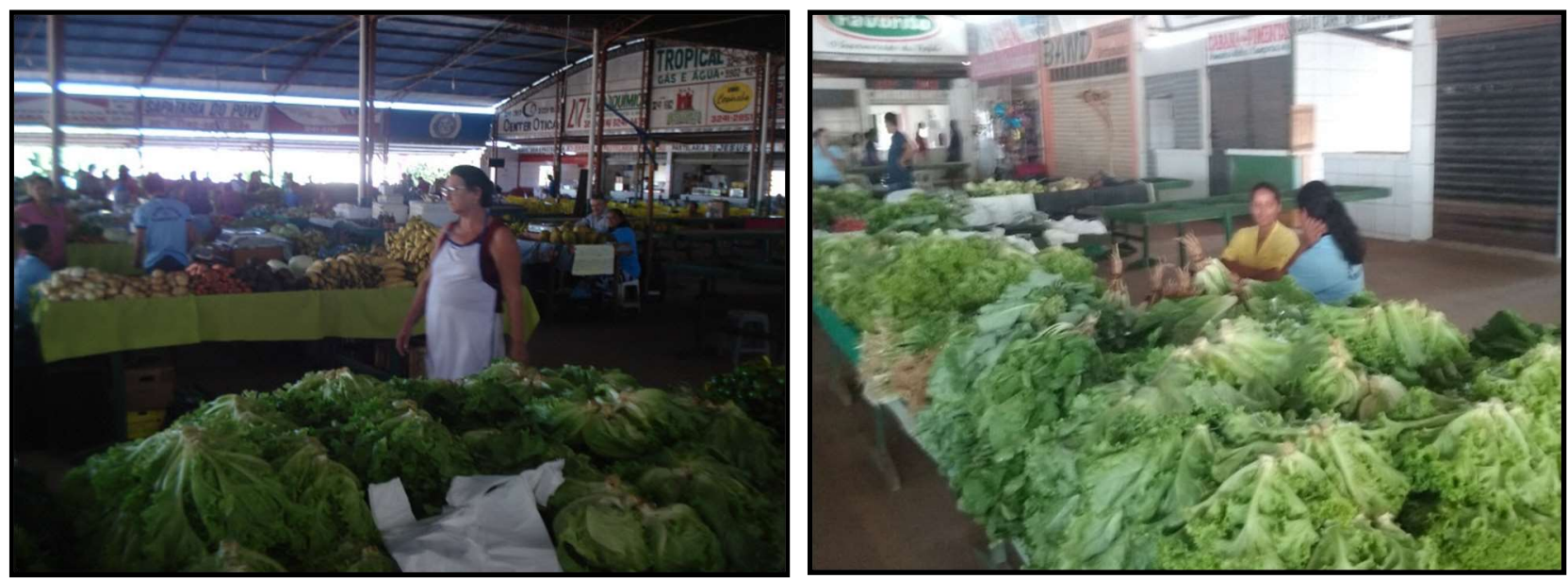

Figura 3: Agricultoras da Associação de Hortifrutigranjeiros no município de Mirassol D’ Oeste/MT. Fonte: a autora (2016).

As agricultoras relataram não conseguirem dar sequência nos estudos em virtude do trabalho doméstico e rural (Tabela 3). Todavia, algumas expuseram o interesse em voltar a estudar futuramente, pois acreditam que a vida pode melhorar através dos cursos técnicos profissionalizantes, cuja carga horária pode ser realizada em menor prazo.

Tabela 3: Grau de escolaridade das mulheres da Associação de hortifrutigranjeiros no município de Mirassol D’Oeste, MT.

\begin{tabular}{|c|c|c|}
\hline Escolaridade das associadas & FA & FR (\%) \\
\hline Ensino Primário & 10 & 43,47 \\
\hline Ensino Fundamental & 3 & 13,04 \\
\hline Ensino Médio & 6 & 26,08 \\
\hline Não alfabetizada & 1 & 4,34 \\
\hline Recusas & 3 & 13,04 \\
\hline Total & 23 & 100 \\
\hline
\end{tabular}

O percentual de agricultoras da Associação de Hortifrutigranjeiros que concluíram o Ensino Primário aponta a necessidade de incentivo através de convênios e parcerias com instituições responsáveis, para que estas possam melhorar a condição de vida em aspectos sociais e econômicos, visando a garantia na qualidade de vida. Nesse contexto, Siliprandi (2004, p.8), afirmou que:

O modelo "idealizado" de família que vigorou no período entre guerras (do homem dedicado ao trabalho assalariado e da mulher dona de casa) foi sendo transformado pela crise econômica e social que se seguiu, pela necessidade de as mulheres trabalharem e pela emergência dos movimentos de mulheres, que reivindicaram o acesso ao mercado de trabalho.

As agricultoras familiares da Associação de Hortifrutigranjeiros do município mato-grossense de Mirassol D’Oeste/MT, afirmam serem as principais responsáveis na produção de alimentos comercializados em seus espaços produtivos.

Segundo Oakley (2004) as mulheres em diversas culturas são as principais responsáveis por exercerem e manterem a prática do cultivo doméstico, o que indica a qualidade do alimento cultivado, como atividade terapêutica, complemento na renda familiar ou mesmo como fonte de medicina alternativa natural para os familiares. 
Ao que tange a organização das mulheres na Associação de Hortifrutigranjeiros no município de Mirassol D'Oeste/MT, estas afirmaram não participarem de reuniões específicas para mulheres rurais e sentem que há essa necessidade e, enfatizam que os órgãos públicos em esfera municipal, via parcerias no âmbito rural, deveriam oferecer orientação técnica agrícola e cursos profissionalizante para que elas possam aprimorar o trabalho que exercem na Associação. O que promoveria, segundo os esforços preconizados pelo Pnud (2014, s/p.), a igualdade de gênero, a democracia igualitária e, principalmente, a resiliência quanto a sustentabilidade.

Souza et al. (2011) afirmaram que embora a agricultura familiar seja importante esta enfrenta desafios que dificultam o seu avanço, dentre eles cita-se a falta de orientações técnicas e as limitações de recursos financeiros e de acesso tecnológico. As mulheres têm aspirações relativas ao aprofundamento do conhecimento das técnicas de produção, como expressado por R. S. R. (32 anos):

Eu cresci no sítio e hoje também vivo da agricultura familiar, casei cedo, mas, ainda quero estudar para entender melhor de pragas, pra poder vender as verduras mais bonitas, sem usar tanto veneno.

Siliprandi (2009) apontou que, o que se legitima na zona rural é o princípio de que é dever da mulher o cuidar doméstico, assim não podem assumir a responsabilidade das atividades agrícolas. Essa situação se repete com as mulheres, conforme depoimento de M. R. S. (46 anos), há 12 anos na Associação:

Meu marido que planta eu fico apenas com a parte da comercialização porque tenho que cuidar de casa também.

Woortmann (1995) evidenciou que o trabalho da mulher do campo não tem reconhecimento nas atividades agrícolas, o que torna um desafio à discriminação sexual do trabalho, sendo este notoriamente considerado como do sexo masculino. Relativo ao conhecimento sobre as políticas públicas voltadas às mulheres as agricultoras afirmaram desconhecê-las, conforme exposto pela agricultora G. S. B (48 anos):

Eu não conheço políticas públicas de mulheres e nem sei se existe, só sei que quando alguém precisa de nós, é mesmo só para pedir voto e não volta nunca mais lá no meu sítio, não tenho auxílio para melhorar o que planto e trago para vender na feira.

Em nível federal foi criada em 2003 a Secretaria Especial de Políticas para as mulheres, com status de Ministério, considerada um avanço e o reconhecimento por parte do Estado da importância da proposição de políticas públicas voltadas para a questão de gênero no País, principalmente no combate à Violência contra a Mulher. Esta Secretaria tem apresentado uma atuação relevante nos temas relacionados às mulheres rurais, como o apoio assuas reivindicações junto aos ministérios e órgãos do governo para a titulação da terra em nome da trabalhadora rural e a participação da mulher na produção agrícola. Sobre atuação feminina na política Pintanguy $(2011$, p. 29) discorreu que:

A identidade feminina tem sido marcada, ao longo dos séculos, pela vivência da exclusão do poder institucional. É importante ter presente a carga simbólica que acompanha o exercício do poder e o fato de que a secular ausência da mulher neste espaço tem efeitos perversos na conformação de uma percepção social da mulher como inadequada e incapaz para tais funções.

No âmbito das políticas públicas direcionadas a agricultura familiar no País, o Programa Nacional de Fortalecimento da Agricultura Familiar (Pronaf), criado pelo Decreto no 1.946/1996 (BRASIL, 1996), que tem como viés principal o incentivo ao desenvolvimento sustentável do segmento rural constituído pelos 
agricultores familiares, com objetivo de garantir o aumento na produção agrícola, o que visa garantir o aumento nos índices na geração de empregos e consequentemente, a qualidade de vida para a população campesina.

Assim, sobre essa política as agricultoras em sua grande maioria afirmaram ter conhecimento, mas desconhecem a forma de ter acesso, por exemplo, a política pública Pronaf - Mulher, pois, não ocorre encontro das mulheres enquanto articuladoras na Associação de Hortifrutigranjeiros no município de Mirassol D’Oeste/MT, estas mencionam a falta de incentivo de órgãos competentes para que possam reunir em assembleias e definir metas de ações que possam fortalecer o grupo de mulheres da referida Associação a exemplo de outros grupos organizados como Margarida Alves no mesmo município. Diante disso, o requisito para se configurar como agricultor familiar e poder benefícios previstos na legislação são:

Exercer atividades no meio rural; não possuir área maior do que quatro módulos fiscais; que a mão de obra a lida com a terra seja de base familiar; que a renda familiar seja originada de atividades econômicas realizadas no estabelecimento e que o agricultor gerencie o estabelecimento em família; com base nos seguintes princípios: "I - Descentralização; II Sustentabilidade ambiental, social e econômica; III - Equidade na aplicação das políticas, respeitando os aspectos de gênero, geração e etnia; IV - Participação dos agricultores familiares na formulação e implantação da política nacional da agricultura familiar e empreendimentos rurais". (BRASIL, 2006)

No ano de 2003 foi criada a linha de ação no PRONAF denominada: "Pronaf Mulher", que foi considerada um avanço, pois até então o acesso ao crédito era concedido somente a um membro da família, sendo este, o "homem denominado o chefe da família", o que configura o início do rompimento ao patriarcalismo histórico no País (BRUMER, 2004).

As políticas públicas mencionadas, se ativas, promovem o desenvolvimento de produtos novos e diferenciados da agricultura familiar visando à inserção nas cadeias produtivas do atual mercado econômico brasileiro que apresenta instabilidade financeira, bem como a estruturação e organização socioeconômica do grupo de agricultoras na Associação de Hortifrutigranjeiros no município de Mirassol D’ Oeste/MT.

Em outras regiões brasileiras, essas políticas públicas têm se apresentado com falhas e não tão eficiente, mas, são possibilidades para o desenvolvimento dessas localidades, a exemplo da atuação de mulheres sulistas que enfrentaram grandes desafios para que hoje sejam referências em âmbito nacional, bem como as mulheres extrativistas (ARPEP) na região sudoeste mato-grossense, o grupo das margaridas e outras representatividades importantes no segmento das mulheres rurais.

\section{CONCLUSÕES}

As discussões voltadas para as questões de gênero, agricultura familiar e política pública têm avançado nos últimos anos, contudo ainda será necessário tempo para que surtam efeitos e aja mudança na sociedade relativa à invisibilidade do trabalho feminino no campo.

Alguns grupos de mulheres que atuam na região que abrange a área de estudo, como as da ARPEP e Margarida Alves, têm obtido êxito no reconhecimento de seu trabalho, por meio de ações que foram apoiadas por instituições ligadas a pesquisa e pelos movimentos sociais. Tendo como referência o exposto, 
as mulheres investigadas acreditam num futuro próspero, contudo as suas filhas não demonstram na atualidade desejo de dar prosseguimento as atividades de suas progenitoras.

Verificou-se que, há participação das agricultoras da Associação de Hortifrutigranjeiros em Mirassol D’Oeste/MT na geração de renda familiar, advinda do trabalho na terra.

Há necessidade de mobilização/organização das agricultoras para ampliação do acesso às políticas públicas, tanto de geração de renda como de profissionalização, para que exerçam suas atividades no campo.

Constatou-se que as agricultoras da Associação de Hortifrutigranjeiros anseiam adquirir conhecimentos sobre as técnicas de manejo e produção, o que poderia contribuir na sustentabilidade nos espaços produtivos, atendimento da demanda local e regional.

\section{AGRADECIMENTOS}

Ao projeto de extensão: "Núcleo de extensão em Desenvolvimento Territorial da grande Cáceres: uma estratégia de desenvolvimento sustentável por meio de ações que fortaleçam a produção agroecológica, agroindustrialização, comercialização e a atuação das mulheres" financiado no âmbito do Edital CNPq/MDA/ SPM n ${ }^{0} \cdot 11 / 2014$ - Apoio a implantação e manutenção de núcleos de extensão em desenvolvimento territorial. À Associação de Hortifrutigranjeiros. À Prefeitura municipal de Mirassol D’Oeste-MT.

In memoriam ao Prof. Dr. Ronaldo José Neves, orientador da pesquisa de Dissertação intitulada: Agricultura familiar na Associação de Hortifrutigranjeiros no município de Mirassol D'Oeste - MT, Brasil, meu mestre cujos ensinamentos e humildade ficam como exemplo para que possa seguir o seu legado.

\section{REFERÊNCIAS}

BRASIL. Instituto Brasileiro de Geografia e Estatística. Censo Demográfico 2010. Agregado de setores censitários dos resultados do universo. 2016

BRASIL. Lei n.o 11.326, de 24 de julho de 2006. Estabelece as diretrizes para a formulação da política nacional da agricultura familiar e empreendimentos familiares rurais. 2006.

BRITO, J. C.. Enfoque de gênero e relação saúde/trabalho no contexto de reestruturação produtiva e precarização do trabalho. Caderno de Saúde Pública, Rio de Janeiro, v.16, n.1, 2000

BRUMER, A.; ANJOS, G.. Gênero e agricultura: a situação da mulher na agricultura do Rio Grande do Sul. Estudos

Feministas, Florianópolis, v.12, n.1, p.36-42, 2004.

BUAINAIN, A. M., ROMEIRO, A. R., GUANZIROLI, C. Agricultura familiar e o novo mundo rural. Sociologias, Porto Alegre, v.5, n.10, p.312-347, 2003.

CARMO, M. S.. A produção familiar como locus ideal da agricultura sustentável. In: BRANDERBURG, A. Para pensar outra agricultura. Curitiba: UFPR, p.12-23, 2001.

CHOINASKI, L.. Uma experiência prática de luta. In: BORBA A.. Mulher e política: gênero e feminismo no Partido dos Trabalhadores. São Paulo: Perseu Abramo, 1998.
CINTRÃO, R.; SILIPRANDI, E.. O progresso das mulheres rurais. In: BARSTED, L.; PITANGUY, J.. O Progresso das Mulheres no Brasil 2003- 2010. Rio de Janeiro: CEPIA; Brasília: ONU Mulheres, 2011.

COLEMAN, J. S.. Snowball sampling: problems and techniques chain referral sampling. Human Organization, San Francisco, v.17, n.4, p 28-26, 1958.

ESRI. ArcGis 10.4. Redlands: Environmental Systems Research Institute, 2016.

GOODMAN, L. A.. Snowball sampling. The annals of mathematical statistics, p.148-170, 1961.

KREITLOW, J. P.. Diagnóstico do município de Mirassol D'Oeste para fins de planejamento ambiental. Dissertação (Mestrado em Ambiente e Sistemas de Produção Agrícola) Universidade do Estado de Mato Grosso, Tangará da Serra, 2015.

MARCONI, M. A.; LAKATOS E. M.. Fundamentos de metodologia científica. São Paulo: Atlas, 2007.

MATO GROSSO. Secretaria de Estado de Planejamento e Coordenação Geral. Plano de Longo Prazo de Mato Grosso: macro-objetivos, metas globais, eixos estratégicos e linhas estruturantes. In: PRADO, J. G. B.; BERTCHIELI, R.; OLIVEIRA, 


\section{G.. Plano de Longo Prazo de Mato Grosso. Cuiabá:} Central de Texto, 2012.

MENDES, M. F.; NEVES, S. M. A. S.; NEVES, R. J.; SILVA T. P.. A organização das mulheres extrativistas na região Sudoeste mato-grossense, Brasil. Estudos Feministas, Florianópolis, v.22, n.1, p.71-89, 2014.

OAKLEY, E.. Quintais domésticos: uma responsabilidade cultural. Agriculturas, Rio de Janeiro, v.1, n.1, p.37-39, 2004.

OLIVEIRA, L. S.; MATSUMOTO, S. N.; SILVA, R. A.; SILVA, V. A.; OLIVEIRA, P. N.. Métodos para quantificação e interpretação da distribuição espacial de cobertura do solo em cafezais arborizados. Coffee Science, Lavras, v.9, n.2, p.168-177, 2014

ONU. United Nations Development Programme. Human development report 1999. New York: Oxford University Press, 1999.

PACHECO, M. E. L.; CARDOSO, E. M.. A sustentabilidade da produção agroecológica também é uma questão de gênero. Revista Ação Ambiental, Viçosa, v.8, n.31, p.30-33, 2005.

PITANGUY, J.. Advocacy e direitos humanos. In: O Progresso das Mulheres no Brasil 2003-2010. Rio de Janeiro: CEPIA; Brasília: ONU Mulheres, 2011.

PNUD. Programa das Nações Unidas para o Desenvolvimento. Empoderamento das mulheres. 2014

SCHNEIDER, S.. Teoria social, agricultura familiar e pluriatividade. Revista Brasileira de Ciências Sociais, São Paulo, v.18, n.51, p.99-121, 2003.

SCOTT, P.; CORDEIRO, R.; MENEZES, M. A.. Gênero e geração em contextos rurais. Editora Mulheres, 2010.

SCOTT, P.; CORDEIRO, R.; MENEZES, M. A.. Um olhar de gênero e de geração nos universos rurais. Revista Estudos Feministas, Florianópolis, v.20, n.2, p.589-592, 2012.
SILIPRANDI, E.. Mulheres e Agroecologia: a construção de novos sujeitos políticos na agricultura familiar. Tese (Doutorado em Desenvolvimento Sustentável) Universidade de Brasília, Brasília, 2009.

SILIPRANDI, E.. Políticas de segurança alimentar e relações de gênero. Cadernos de Debate, v.11, 2004

SILVA, M. A.; NEVES, R. J.. Políticas públicas para a agricultura familiar na região Sudoeste mato-grossense: realidade e perspectivas. Acta Scientiarum. Human and Social Sciences, Maringá, v.36, n.2, p.125-135, 2014.

SILVA, M. A.. Produção agroindustrial desenvolvida nos assentamentos da região sudoeste: mato-grossense e a atividade de turismo rural. Dissertação (Mestrado em Ambiente e Sistemas de Produção Agrícola) - Universidade do Estado de Mato Grosso, Tangará da Serra, 2014.

SOUSA, E. G.. Políticas públicas voltadas ao homem do campo - o Pronaf em Bananeiras - PB. Monografia (Especialização em Gestão Pública Municipal) - Universidade Aberta do Brasil, 2011.

SPREEN, M.. Rare populations, hidden populations and link tracing designs - What and What?. Bulletin methodologie Sociologique, Oxford, v.36, n.1, p.34-58, 1992.

TAVARES, R. R.. Igualdade de gênero e o Empoderamento das mulheres. In: BARSTED, L.; PITANGUY, J.. O Progresso das Mulheres no Brasil 2003-2010. Rio de Janeiro: CEPIA; Brasília: ONU Mulheres, 2011.

TEIXEIRA, E. C.. O papel das políticas públicas no desenvolvimento local e na transformação da realidade. Cadernos da Associação de Advogados de Trabalhadores Rurais no Estado da Bahia, Salvador, p.1-10, 2002.

WOORTMANN, E. F.. Herdeiros, Parentes e Compadres: colonos do Sul e sitiantes do Nordeste. São Paulo: Hucitec, 1995.

YIN, R. K.. Estudo de caso: planejamento de métodos. 4 ed Porto Alegre: Bookman, 2010. 